\title{
Desempenho e digestibilidade aparente em ovinos confinados alimentados com dietas contendo níveis crescentes de caroço de algodão integral
}

\author{
Maria das Graças Gomes Cunha ${ }^{1}$, Francisco Fernando Ramos de Carvalho ${ }^{2}$, Antonia \\ Sherlânea Chaves Véras ${ }^{2}$, Ângela Maria Vieira Batista ${ }^{2}$
}

\footnotetext{
${ }^{1}$ Empresa Estadual de Pesquisa Agropecuária da Paraíba

2 DZ/UFRPE.
}

RESUMO - Este trabalho foi realizado com o objetivo de avaliar os efeitos de dietas com diferentes níveis (0,0; 20,0; 30,0 e $40,0 \%$ ) de caroço de algodão integral (Gossypium hirsutum L.) na matéria seca da dieta sobre o desempenho, consumo e a digestibilidade dos nutrientes de ovinos Santa Inês. Vinte e quatro cordeiros inteiros com peso corporal médio inicial de 19,5 kg foram submetidos a um delineamento inteiramente casualizado, com quatro dietas e seis repetições. Os consumos de matéria seca, expressos em kg/dia, \%PV e g/ $\mathrm{kg}^{0,75}$, não foram influenciados pela inclusão do caroço de algodão integral (CAI), com médias de 1,195; 4,61 e 104,07, respectivamente. Os ganhos de peso total e diário decresceram, enquanto a conversão teve efeito linear crescente, mas entre os níveis de CAI o de $20 \%$ apresentou desempenho semelhante à dieta controle. Os consumos de matéria orgânica (MO), proteína bruta (PB), carboidratos totais (CHT) e nutrientes digestíveis totais, expressos em g/dia, não foram afetados, enquanto os de fibra em detergente neutro (FDN), fibra detergente ácido (FDA) e extrato etéreo (EE) tiveram efeito linear crescente com a adição do CAI. A inclusão do caroço de algodão na alimentação proporcionou efeito quadrático para os coeficientes de digestibilidade de PB e FDA e linear crescente para FDN e EE, porém não afetou os de MS, MO e CHT e o consumo de NDT. O CAI nos níveis utilizados não alterou o consumo e a digestibilidade de MS, FDN e NDT, mas reduziu o ganho de peso e a eficiência alimentar de ovinos em terminação.

Palavras-chave: consumo, ganho de peso, gossipol, oleaginosas, Santa Inês

\section{Performance and apparent digestibility of feedlot sheep fed with different dietary whole cotton seed levels}

\begin{abstract}
This work was carried out with the objective to evaluate the effects of different levels $(0.020 .0,30.0$ and $40.0 \%$ ) of whole cottonseed (Gossypium hirsutum L.) of the diet (\% DM) on performance and nutrient digestibilities of feedlot Santa Inez sheep. Twenty-four sheep with average initial and final body weight of 19.0 and $32.2 \mathrm{~kg}$, respectively, and allotted to a completely randomized design, with four diets and six replications. The dry matter intake in $\mathrm{kg} / \mathrm{day}$, \%BW and $\mathrm{g} / \mathrm{kg}^{0.75}$ was not influenced by the inclusion of the whole cottonseed (WCS), with averages of 1.195 , 4.61, and 104.07, respectively. The total and daily weight gains decreased, while the feed conversion ration showed increasing linear effect with the inclusion of WCS, except for the level of $20 \%$ WCS that showed similar performance to the control diet. The intakes of dry matter (DM), organic matter (OM), crude protein (CP), total carbohydrates (TC) and total digestible nutrients (TDN), in g/day were not affected, while the neutral detergent fiber (NDF), acid detergent fiber (ADF), ether extract (EE) presented increasing linear effect with the inclusion of WCS. The inclusion of whole cottonseed in the feeding provided quadratic effect for digestible coefficients of CP, ADF and increasing linear effect for NDF and EE, however did not affect DM, OM, TC and TDN intake of the diets. The whole cottonseed in the used levels does not alter the intake and the digestibility of the DM, NDF and TND, but reduced the weight gain and feed conversion ratio of feedlot of the Santa Inez lambs, and could be included in termination diets.
\end{abstract}

Key Words: gossypol, intake, oleaginous legumes, Santa Inez, weight gain

\section{Introdução}

Uma estratégia utilizada para a melhoria do desempenho dos rebanhos nordestinos de pequenos ruminantes, caracterizados por baixos índices produtivos, seria o manejo alimentar adequado, principalmente nas épocas secas de escassez de forragens, usando-se sistemas intensivos de produção, como o confinamento ou semi-confinamento. 
Surge, então, a necessidade de estudar a viabilidade de incluir fontes alimentares alternativas e quantificar a resposta animal em termos produtivos e econômicos. Uma das opções são os subprodutos da agroindústria; porém, estes ainda não foram suficientemente estudados quanto à sua composição e níveis adequados de utilização econômica e biológica na produção animal, especialmente em caprinos e ovinos.

$\mathrm{O}$ adequado desempenho produtivo dos ruminantes está relacionado principalmente ao consumo alimentar, que, por sua vez, depende do consumo de matéria seca (MS) e de sua concentração energética. As oleaginosas são as fontes de lipídios mais usadas na dieta de ruminantes, por proporcionarem alta densidade energética em substituição aos carboidratos rapidamente fermentáveis, favorecendo a fermentação ruminal e a digestão da fibra, entretanto, não deve ser usado em excesso, devido ao seu conteúdo em óleo (Teixeira, 2005).

Diversos autores comentaram que a adição do caroço de algodão integral (CAI) às rações, à proporção de 25 a 30\% da dieta total, mantém o nível de ingestão de MS e aumenta a energia líquida ingerida, a porcentagem de gordura do leite, a produção de leite e a digestibilidade do extrato etéreo (EE) da dieta, não havendo alteração na digestibilidade da fibra, em razão de o CAI ser um alimento com altos teores de energia e fibra de alta digestibilidade (Palmiquist \& Jenkins,1980; Smith et al., 1981; Coppock et al., 1987; Wilks et al., 1991; Arieli, 1998).

Trabalhando com ovinos, Warren et al. (1988) testaram níveis de 0; 25 e 50\% de CAI na dieta e constataram que, em proporção de até $25 \%$, a ingestão e as digestibilidades da MS e matéria orgânica (MO) não foram afetadas. Os ganhos de peso foram superiores à dieta controle, com ótimos resultados no crescimento da lã.

Arieli (1994) verificou que a inclusão do CAI (níveis acima de $25 \%$ do total da matéria seca) em dietas de ovinos não promoveu efeito sobre o coeficiente de digestibilidade aparente da energia bruta; resultado também obtido por Smith et al. (1981). Zinn \& Plascencia (1993) observaram que a inclusão do CAI (20\% do total da dieta) em dietas compostas de feno de alfafa, cevada, milho, melaço de cana, sal comum e sal mineral diminuiu significativamente a digestibilidade de MO das dietas. Porém, houve elevação na taxa de passagem de material nitrogenado ao intestino delgado, em razão do aumento de $37,5 \%$ da síntese de proteína microbiana, corroborando as afirmações de Zinn (1989).

Karalazos et al. (1992) observaram diminuição linear dos coeficientes de digestibilidade aparente de MS, MO e
EB com o aumento dos níveis dietéticos de caroço de algodão. Em função da alta densidade energética das dietas com CAI, não houve efeito do caroço sobre o consumo de energia digestível. Moore et al. (1986) e Brosh et al. (1989) também observaram diminuição na digestibilidade de MS, $\mathrm{MO}$ e EB em bezerros alimentados com dietas contendo CAI.

Atualmente, pesquisas sobre o uso de CAI na dieta de pequenos ruminantes ainda são escassas. Portanto, este trabalho foi realizado com o objetivo de avaliar os efeitos de diferentes níveis de caroço de algodão integral sobre o desempenho, consumo e os coeficientes de digestibilidade aparente dos nutrientes em ovinos Santa Inês em confinamento.

\section{Material e Métodos}

O trabalho foi conduzido na Estação Experimental de Pendência da Empresa Estadual de Pesquisa Agropecuária da Paraíba-EMEPA - PB, na microrregião do Cariri Paraibano, no município de Soledade, situada a $7^{\circ} 8^{\prime} 18^{\prime \prime S}, 36^{\circ} 27^{\prime 2} 2$ 'W.Gr e altitude em torno de $534 \mathrm{~m}$, com temperatura média ao longo do ano de $30^{\circ} \mathrm{C}$ e umidade relativa do ar de $68 \%$. O clima da região é classificado como semi-árido quente, de 7 a 8 meses secos, com chuvas de verão, e precipitação anual de 350 a $600 \mathrm{~mm} /$ ano.

Foram utilizados 24 cordeiros inteiros Santa Inês, machos, com peso corporal médio inicial de 19,5 kg e quatro meses de idade, distribuídos em delineamento inteiramente casualizado com quatro dietas e seis repetições. Após realização das medidas sanitárias contra endo e ectoparasitas e vacinação contra clostridiose, os animais foram alojados em baias individuais $(0,80 \times$ $1,20 \mathrm{~m}$ ), dispostas em galpão de alvenaria e providas de comedouros e bebedouros. O período experimental (70 dias) foi precedido de 14 dias para adaptação ao manejo e às dietas. As pesagens dos animais ocorreram a cada 14 dias a partir do início do experimento.

A ração foi fornecida com base em $5 \%$ do peso corporal, distribuída em duas refeições diárias (8 e 16 h); as sobras foram pesadas e registradas na manhã do dia seguinte. Amostras das dietas e sobras foram coletadas semanalmente, processadas e armazenadas para posteriores análises. Ao final do ensaio, foram feitas amostras compostas por período, submetidas a análises bromatológicas no laboratório de Nutrição Animal da Universidade Federal da Paraíba.

As determinações de MS, proteína bruta (PB), matéria mineral (MM) e EE foram efetuadas segundo metodologia descrita por Silva \& Queiroz (2002). Para determinação das 
fibras em detergente neutro (FDN) e detergente ácido (FDA), utilizou-se a metodologia descrita por Van Soest et al.(1991), recomendada pelo fabricante do aparelho ANAKON, porém utilizando-se sacos de náilon. Foi utilizada alfa amilase para as determinações de FDN dos ingredientes concentrados e da palma forrageira. Em todas as amostras, a FDN foi corrigida para proteína. Os teores dos compostos nitrogenados insolúveis em detergente neutro (NIND) foram estimados nos resíduos obtidos da FDN, por intermédio do método Kjeldahl.

As dietas (Tabela 1 ) foram formuladas com a inclusão de níveis crescentes de caroço de algodão $(0 ; 20 ; 30$ e $40 \%$ ), com base na matéria seca, e compostas de palma forrageira (Opuntia ficus indica MILL), feno de Tifton-85 (Cynodon spp), milho triturado, farelo de soja, uréia e minerais (Tabela 2), segundo o NRC (1985), para atender às exigências de proteína e energia metabolizável dos animais para ganho de $150 \mathrm{~g} / \mathrm{dia}$. Avaliaram-se o consumo de matéria seca (CMS), em kg/dia, \%PC e g/ $\mathrm{kg}^{0,75}$; ganho em peso médio diário (GPMD), em kg/dia; e conversão alimentar (CA).

Ao final do ensaio de desempenho, os animais foram transferidos para gaiolas de estudos metabólicos, providas de comedouros e bebedouros e com dispositivo para coleta de fezes, e receberam os mesmos tratamentos experimentais do ensaio anterior, uma vez que estavam adaptados às dietas. Houve um período de sete dias para adaptação às gaiolas, seguido da fase de coleta de dados e amostras, com duração de sete dias. Os animais receberam alimentação diariamente, às 8 e 16 h, e água à vontade. Durante o fornecimento, a palma foi previamente cortada com faca de aço inoxidável e misturada aos demais ingredientes, de modo que houvesse sobras de $10 \%$.

Os animais foram pesados no início do período de adaptação, servindo de referência para o cálculo do consumo de MS, em kg/dia, e conseqüente ajuste da quantidade de

Tabela 1 - Composição nutricional dos ingredientes das dietas (\% MS)

\begin{tabular}{lcccccccccc}
\hline Ingrediente & MS & MO & MM & PB & EE & FDN & FDN $_{P}$ & FDA & CNF & NDT \\
\hline Feno de capim Tifton 85 & 93,6 & 96,3 & 3,7 & 9,6 & 1,6 & 76,9 & 73,5 & 37,0 & 11,6 & $48,5^{1}$ \\
Milho moído & 91,1 & 97,3 & 2,7 & 10,8 & 5,1 & 9,7 & 8,1 & 4,3 & 73,3 & $85,1^{1}$ \\
Farelo de soja & 89,7 & 92,8 & 7,2 & 51,2 & 2,4 & 14,4 & 11,5 & 10,0 & 27,7 & $81,5^{1}$ \\
Caroço de algodão integral & 93,1 & 96,9 & 3,1 & 27,8 & 20,0 & 46,5 & 43,0 & 35,0 & 6,1 & $86,2^{1}$ \\
Palma forrageira & 10,3 & 87,5 & 12,5 & 4,8 & 1,8 & 27,2 & 26,1 & 21,2 & 54,8 & $65,2^{1}$ \\
\hline
\end{tabular}

FDNp = fibra em detergente neutro corrigida para proteína; CNF = carboidratos não-fibrosos; NDT = nutrientes digestíveis totais.

${ }^{1}$ Estimado pela equação de Weiss (1999).

Tabela 2 - Composições em ingredientes e nutricional das dietas experimentais com diferentes níveis de caroço de algodão integral, $\%$ MS

\begin{tabular}{|c|c|c|c|c|}
\hline \multirow{2}{*}{$\begin{array}{l}\text { Item } \\
\text { Ingrediente (\% MS) }\end{array}$} & \multicolumn{4}{|c|}{ Nível de caroço de algodão (\%) } \\
\hline & 0 & 20 & 30 & 40 \\
\hline Feno de capim-Tifton 85 & 33,10 & 30,50 & 36,60 & 31,20 \\
\hline Grão de milho moído & 32,60 & 21,60 & 6,40 & - \\
\hline Farelo de soja & 7,80 & - & - & - \\
\hline Caroço de algodão & 0 & 20,00 & 30,00 & 40,00 \\
\hline Palma forrageira & 24,40 & 25,00 & 25,20 & 25,80 \\
\hline Uréia & 1,10 & 1,00 & 0,80 & 0,50 \\
\hline Calcário calcítico & 0,50 & 1,40 & 0,50 & 2,00 \\
\hline Mistura mineral ${ }^{1}$ & 0,50 & 0,50 & 0,50 & 0,50 \\
\hline \multicolumn{5}{|l|}{ Composição } \\
\hline Energia metabolizável (Mcal de EM/kg de MS) & 2,39 & 2,40 & 2,37 & 2,40 \\
\hline Matéria seca (\%) & 31,40 & 30,90 & 30,80 & 30,30 \\
\hline Proteína bruta (\%) & 15,00 & 15,00 & 15,90 & 16,70 \\
\hline Extrato etéreo (\%) & 2,90 & 6,00 & 7,40 & 9,00 \\
\hline FDN corrigida para proteína (\%) & 36,40 & 41,60 & 49,60 & 49,60 \\
\hline Fibra em detergente ácido (\%) & 19,80 & 24,90 & 30,10 & 31,70 \\
\hline Carboidratos totais (\%) & 75,20 & 71,60 & 70,10 & 66,20 \\
\hline Carboidratos não-fibrosos (\%) & 41,00 & 32,30 & 23,20 & 19,40 \\
\hline Matéria mineral & 6,90 & 7,40 & 6,60 & 8,10 \\
\hline Nutrientes digestíveis totais (\%) & 66,10 & 66,72 & 65,50 & 66,43 \\
\hline
\end{tabular}

${ }^{1}$ Níveis de garantia (nutrientes/kg): cálcio $130 \mathrm{~g}$; fósforo $70 \mathrm{~g}$; magnésio $1.320 \mathrm{mg}$; ferro $2.200 \mathrm{mg}$; cobalto $140 \mathrm{mg}$; manganês 3,690 mg; zinco $4.700 \mathrm{mg}$; iodo $61 \mathrm{mg}$; selênio $45 \mathrm{mg}$; enxofre $12 \mathrm{~g}$; sódio $170 \mathrm{~g}$; cloro $276 \mathrm{~g}$; flúor máximo $700 \mathrm{mg}$; solubilidade mínima de $\mathrm{P}_{2} \mathrm{O}_{5}$ em ácido cítrico a $2 \%=90 \%$. 
sobras. Amostras dos alimentos e das sobras foram retiradas diariamente às $8 \mathrm{~h}$, pesadas e guardadas em sacos plásticos; no final do período, foi preparada uma amostra composta para cada unidade experimental, desidratada em estufa de ventilação forçada, a $65^{\circ} \mathrm{C}$, durante 72 horas. Posteriormente, foram processadas em moinhos de facas tipo Willey com peneira de malha de $1 \mathrm{~mm}$ e acondicionadas para análises laboratoriais.

As fezes foram coletadas diariamente durante sete dias; a produção total teve o peso registrado, com reserva de $20 \%$ do total coletado. Ao final, foi preparada uma amostra composta por animal, que foi embalada em sacos plásticos individuais e armazenada em câmara fria a $-10^{\circ} \mathrm{C}$. Após o descongelamento, foram processadas em peneira de malha grossa, homogeneizadas, pesadas, acondicionadas em bandeja de alumínio e secas em estufa de ventilação forçada a $65^{\circ} \mathrm{C}$.

Para estimativa dos carboidratos totais (CHT), foi usada a equação proposta por Sniffen et al. (1992), CTH= 100 - (\%PB +\%EE+\%MM), epara estimativa dos carboidratos não-fibrosos (CNF), a equação preconizada por Hall et al. (1999), CNF = \% CHT- \% FDNp, sendo a FDN corrigida para proteína.

Para o cálculo dos nutrientes digestíveis totais (NDT), utilizou-se a equação proposta por Weiss (1999), $\mathrm{NDT}=(\mathrm{PBD}+\mathrm{CNFD}+\mathrm{FDNpD}+(\mathrm{EED} * 2,25)$, em que PBD, CNFD, FDNp e EED significam, respectivamente, consumos de PB, CNF, FDN e EE digestíveis, sendo a FDN corrigida para proteína.

O delineamento experimental adotado foi o inteiramente casualizado, com quatro tratamentos e seis repetições, com análises de variância e regressão em função dos níveis de caroço de algodão na dieta. Os critérios utilizados para a escolha dos modelos foram o comportamento biológico, o coeficiente de determinação e a significância para os parâmetros de regressão, obtidas pelo teste F, a 1 e 5\% de probabilidade. As análises estatísticas foram feitas com o auxílio do programa Statistical Analysis System (SAS, 1999).

\section{Resultados e Discussão}

Os consumos de matéria seca (CMS), em kg/dia, \%PC e g $/ \mathrm{kg}^{0,75}$, e de matéria orgânica ( $\mathrm{kg} / \mathrm{dia}$ ) não foram afetados pelos níveis de CAI, apresentando médias de 1,195; 4,61; 104,07 e 1,107, respectivamente (Tabela 3). A inibição do consumo nos níveis mais altos de inclusão de CAI pode ser explicada pelo aumento no teor de lipídeo das rações, que, no caso dos maiores níveis, ultrapassou 6\% de lipídios na dieta total. Palmquist (1988) destaca que os efeitos negativos dos lipídios se acentuam a partir deste nível.

As ingestões de MS foram consideradas adequadas quando comparada à recomendação do NRC (1985), de $1,0 \mathrm{~kg}$ de MS/dia para animais de $20 \mathrm{~kg}$ PC, e semelhantes às encontradas por Verás et al.(2005), que obtiveram valores médios de 1,150 kg/dia, para ovinos na mesma faixa de peso, alimentados com dietas contendo farelo de palma em substituição ao milho. Para o consumo de MS por unidade de tamanho metabólico, foram encontrados valores de 105,5; 107; 100 e 103,4 g/kg0,75, em função dos níveis de caroço de algodão. Estes resultados foram superiores aos encontrados por Rogério et al. (2002) e Teixeira (2005), que trabalharam com níveis de CAI na dieta de ovinos semelhantes aos deste ensaio. Os consumos médios diários de MS e MO apresentaram comportamento semelhante, não sendo afetados pela inclusão do CAI, corroborando resultados obtidos por Souto et al. (1990) e Sridhar et al. (1996).

Os ganhos de peso total e médio diário decresceram ( $\mathrm{P}<0,05)$, em função dos níveis dietéticos de CAI (Tabela 3).

Tabela 3 - Consumos de matéria seca (MS) e matéria orgânica (MO) e desempenho animal, em função dos níveis de caroço de algodão integral na dieta

\begin{tabular}{|c|c|c|c|c|c|c|c|}
\hline \multirow[t]{2}{*}{ Item } & \multicolumn{4}{|c|}{ Nível de caroço de algodão integral (\%) } & \multirow[b]{2}{*}{ Regressão } & \multirow[b]{2}{*}{$\mathrm{R}^{2}$} & \multirow[b]{2}{*}{ CV (\%) } \\
\hline & 0 & 20 & 30 & 40 & & & \\
\hline Consumo de MS (kg/dia) & 1,226 & 1,236 & 1,126 & 1,192 & $\hat{Y}=1,195$ & - & 6,31 \\
\hline Consumo de MS (g/kg $\mathrm{PC}^{0,75}$ ) & 105,5 & 107,0 & 100,2 & 103,4 & $\hat{\mathrm{Y}}=10,0$ & - & 5,65 \\
\hline Consumo de MO (kg/dia) & 1,139 & 1,142 & 1,052 & 1,094 & $\hat{\mathrm{Y}}=1,107$ & - & 6,36 \\
\hline Ganho de peso total (kg) & 14,40 & 13,05 & 10,45 & 12,20 & $\hat{\mathrm{Y}}=14,19-0,074 * \mathrm{X}$ & 0,90 & 12,00 \\
\hline Ganho de peso médio diário (kg/dia) & 0,206 & 0,186 & 0,149 & 0,174 & $\hat{\mathrm{Y}}=0,2026-0,001058 * \mathrm{X}$ & 0,89 & 12,00 \\
\hline CA (kgMS/kg GPD) & 6,01 & 6,71 & 7,62 & 6,90 & $\hat{\mathrm{Y}}=6,145+0,0295^{* *} \mathrm{X}$ & 0,58 & 10,0 \\
\hline
\end{tabular}

$\mathrm{PC}=$ peso corporal $; \mathrm{CA}=$ conversão alimentar . 
Sabe-se que, entre os fatores envolvidos na regulação do consumo, estão a ingestão de energia pelo animal e a concentração de FDN da dieta - esta é considerada limitante em função de sua lenta degradação e baixa taxa de passagem pelo rúmen.

A redução no GPMD, segundo a equação, foi de apenas 0,010 kg/dia para cada aumento de $1 \%$ de CAI, enquanto a conversão alimentar aumentou 0,029 kg/MS/kgGPD na mesma ordem; o consumo e o ganho de peso refletiram na conversão alimentar, que nos animais alimentados com CAI foram numericamente inferiores aos da dieta controle. Este resultado corrobora os observados por Medeiros et al. (2003), que obtiveram CA de 6,26 e 7,12 nos níveis de substituição do farelo de soja por farelo de girassol na terminação de ovinos Santa Inês.

A redução no ganho foi relativamente pequena (Tabela 3), demonstrando que o caroço de algodão proporcionou, para o grupo com $40 \%$ de inclusão dessa oleaginosa, ganhos de peso médio diário de 174 g, resultado da utilização do lipídio contido no CAI, como fonte de energia. Vale salientar que os ovinos não apresentaram rejeição à ingestão do caroço de algodão, constituindo-se no primeiro alimento a ser consumido, sendo todos os alimentos misturados e disponibilizados aos animais ao mesmo tempo.

Resultados semelhantes foram relatados por Luginbuhl et al. (2000), que incluíram níveis crescentes de caroço de algodão (0, 8, 16 e 24\%) na dieta de caprinos e observaram redução no ganho de peso corporal e, conseqüentemente, na eficiência alimentar, de acordo com o aumento no nível de CAI na dieta.

Comportamento similar ao obtido nesta pesquisa foi verificado por Brosh et al. (1989), que compararam níveis de CAI em dietas de confinamento, constatando que a inclusão deste alimento acarretou diminuição no ganho de peso, sem alterar o consumo de MS. Estes resultados corroboram os obtidos por Moore et al. (1994), que visualizaram diminuição no ganho de peso corporal e na eficiência alimentar em cordeiros alimentados com níveis crescentes de caroço de algodão (0, 7, 14 e 21\%). Aferri et al. (2005), com bovinos confinados, observaram que o caroço de algodão utilizado em até $21 \%$ nas rações não alterou o desempenho animal.

Também Ludovico \& Matos (1997) verificaram que o CAI em substituição ao farelo de algodão, na proporção de 10 a $20 \%$ da MS total da dieta, melhorou o desempenho animal. Warren et al. (1988), trabalhando com carneiros recebendo dietas suplementadas com trigo e ou caroço de algodão integral (100:0; 75:25 e 50:50\%), respectivamente, observaram que o CAI não afetou o consumo de MS e o ganho de peso foi maior para as dietas com CAI $(4,4$ e 3,0 kg), especialmente para o nível de $25 \%$.

A conversão alimentar apresentou comportamento linear e foi influenciada pelo nível de caroço de algodão na dieta $(\mathrm{P}<0,05)$. Observa-se que a CA piorou à medida que aumentou o teor de FDN da dieta, provavelmente pela adição do feno de Tifton-85, o que está de acordo com Cardoso et al. (2005), que testaram níveis crescentes de FDN (25; 31; 37 e 43\%) na dieta de cordeiros e observaram que o aumento do teor de fibra da dieta reduziu a CA.

O consumo de PB mostrou-se similar em todas as dietas, obtendo-se média de 185,83 g/dia, atendendo à recomendação do NRC (1985), de 167 e 191 g PB/dia, respectivamente, para cordeiros de 20 e $30 \mathrm{~kg}$ PC (Tabela 4). Este resultado corrobora o obtido por Urano et al. (2006), que obtiveram valor médio de 183,7 g/dia em cordeiros Santa Inês alimentados com soja em grãos na dieta, e Petit et al. (1997), que trabalharam com grão de canola e observaram ingestão diária de PB de 175 g/dia para a forma extrusada e 183 g/dia

Tabela 4 - Consumo de nutrientes por ovinos Santa Inês alimentados com diferentes níveis de caroço de algodão integral na dieta

\begin{tabular}{|c|c|c|c|c|c|c|c|}
\hline \multirow[t]{2}{*}{ Item } & \multicolumn{4}{|c|}{ Nível de caroço de algodão integral (\%) } & \multirow[b]{2}{*}{ Regressão } & \multirow[b]{2}{*}{$\mathrm{R}^{2}$} & \multirow[b]{2}{*}{ CV (\%) } \\
\hline & 0 & 20 & 30 & 40 & & & \\
\hline Consumo PB, g/dia & 182,38 & 184,00 & 178,50 & 198,17 & $\hat{\mathrm{Y}}=185,83$ & - & 6,39 \\
\hline Consumo FDN, g/dia & 443,83 & 510,83 & 554,17 & 583,17 & $\hat{\mathrm{Y}}=43,328+3,541^{* *} \mathrm{X}$ & 0,99 & 6,43 \\
\hline Consumo FDA, g/dia & 239,00 & 303,33 & 335,50 & 370,83 & $\hat{\mathrm{Y}}=238,366+3,280 * * \mathrm{X}$ & 0,99 & 6,45 \\
\hline Consumo EE, g/dia & 34,66 & 73,33 & 82,83 & 106,17 & $\hat{\mathrm{Y}}=35,271+1,732 * * \mathrm{X}$ & 0,99 & 6,25 \\
\hline Consumo CNF, g/dia & 499,67 & 397,83 & 258,67 & 228,50 & $\hat{\mathrm{Y}}=508,12-7,198 * * \mathrm{X}$ & 0,99 & 6,49 \\
\hline Consumo $\mathrm{NDT}_{\text {estimado, }}$ g/dia & 715,0 & 7,10 & 745,0 & 786,0 & $\hat{\mathrm{Y}}=739,0$ & - & 6,40 \\
\hline Consumo $\mathrm{NDT}_{\text {observado, }}$ g/dia & 730,0 & 739,0 & 762,0 & 798,0 & $\hat{\mathrm{Y}}=757,0$ & - & 6,90 \\
\hline Consumo $\mathrm{EM}_{\text {estimado, }} \mathrm{Mcal} / \mathrm{dia}$ & 2,58 & 2,56 & 2,69 & 2,84 & $\hat{\mathrm{Y}}=2,66$ & - & 7,92 \\
\hline Consumo EM observado, Mcal/dia & 2,63 & 2,66 & 2,75 & 2,88 & $\hat{\mathrm{Y}}=2,73$ & - & 6,80 \\
\hline Consumo CHT, g/dia & 919,67 & 882,50 & 805,33 & 787,50 & $\hat{\mathrm{Y}}=927,886-3,517 * * \mathrm{X}$ & 0,91 & 7,27 \\
\hline
\end{tabular}

** Significativo a $1 \%$ de probabilidade pelo teste $\mathrm{F}$. 
para a não-extrusada. Esta resposta, provavelmente, ocorreu em virtude da maior seletividade dos animais pelo caroço de algodão, uma vez que o incremento de oleaginosas na dieta melhora o desenvolvimento da flora ruminal e o processo de fermentação.

Comportamento semelhante foi observado para o consumo de NDT, sendo que a incorporação do CAI foi o fator determinante para elevações na concentração de PB e EE da dieta. Este fato é coerente, pois a energia dos alimentos advém dos compostos orgânicos, como PB e EE, já mencionados, e também das frações fibrosas; assim, a elevação dessas frações nas dietas representará maiores teores de energia ingerida.

Os consumos de EE, FDN e FDA aumentaram linearmente $(\mathrm{P}<0,01)$, refletindo o conteúdo mais alto desses nutrientes na dieta dos animais alimentados com maiores níveis de CAI. O consumo de EE, em g/dia, variou de 34,7 a 106,2 g/dia, e a equação de regressão obtida mostra aumento de 1,73 g para cada $1 \%$ de aumento de CAI. Como o EE é a fração que fornece 2,25 vezes mais energia que os carboidratos, o nível de consumo desse nutriente tem relação com o consumo de MS e energia da dieta. Isso também foi relatado por Haddad \& Younis (2004), ao alimentarem cordeiros Awassi com dietas contendo 0,0; 2,5 e 5,0\% de gordura protegida na ração.

Para os consumos de FDN e FDA, a análise de regressão mostrou que a inclusão de CAI na dieta acarretou aumento nos consumos de 3,50 e 3,28 g/dia, respectivamente, em função da maior concentração desses nutrientes na dieta total. Resultados similares para consumo de FDN e FDA foram descritos por Verás et al. (2005), que trabalharam com farelo de palma na dieta de ovinos em confinamento. Também Rodrigues et al. (2003) obtiveram consumos variando de 442,79 a 561,22 g/animal/dia de FDN, utilizando farelo de castanha de caju na terminação de ovinos.

Van Soest (1994) sugere consumo de FDN entre 0,8 e 1,2\% PC, enfatizando que esse limite pode ser ultrapassado, quando a densidade energética da dieta é baixa. O consumo médio de FDN dos ovinos correspondeu a 2,0\% PC, estando de acordo com relatos de Mertens (1994), que considera a FDN um dos principais controladores do consumo de MS pelos ruminantes. Neste trabalho, os maiores consumos de FDN e FDA foram observados nas dietas com maiores níveis de CAI; estes resultados diferem dos obtidos por Borges et al. (2002) e Rogério et al. (2004), que verificaram decréscimos no consumo destes nutrientes, quando se elevaram os níveis de caroço de algodão na dieta.

Embora o percentual de FDN das dietas tenha aumentado em função do nível de CAI aliado ao feno, outros fatores, provavelmente relacionados às características da palma, podem ter influenciado o comportamento dos animais, o que pode ter limitado o consumo de MS, uma vez que a distensão física do rúmen-retículo é considerada um dos principais fatores limitantes do consumo em muitas forragens. Segundo Verás et al. (2002), a palma forrageira apresenta alta palatabilidade e taxa de digestão ruminal, sendo a MS rapidamente degradada, favorecendo maior taxa de passagem.

Os consumos de nutrientes digestíveis totais (NDT) e energia metabolizável (EM) estimados e observados ficaram muito próximos (Tabela 4), podendo inferir-se que a metodologia proposta por Weiss (1999) foi eficiente para estimar o valor energético das dietas. Os valores para o consumo de NDT observados no ensaio de digestibilidade foram de 730,0; 739,0; 762,0 e 798,0 g/dia, enquanto para a EM as ingestões diárias foram de 2,63; 2,66; 2,75 e 2,88 Mcal, evidenciando que a inclusão do CAI nos níveis estudados não afetou o consumo de EM dos animais que receberam as rações à base de palma forrageira e feno de Tifton, ficando dentro dos valores recomendados pelo NRC (1985), para um animal em crescimento com ganho de peso moderado.

Estes resultados de consumo foram superiores aos obtidos por Alves et al. (2003), de 2,18; 2,33 e 2,45 Mcal de EM/dia, trabalhando com ovinos Santa Inês alimentados com dietas contendo diferentes níveis de energia na dieta. Também Medeiros (2006), com ovinos Morada Nova, alimentados com níveis crescentes de concentrado na dieta, obteve consumos de 2,13; 2,61; 2,62 e 3,20 Mcal de EM/dia. Estes resultados, aliados aos de outros estudos, mostraram que é possível atender às necessidades energéticas em sistemas de produção com o uso de alguns recursos forrageiros disponíveis ou alimentos alternativos.

Os consumos de carboidratos totais e não-fibrosos apresentaram comportamento decrescente $(\mathrm{P}<0,01)$, com a inclusão do CAI na dieta; declínio decorrente da diminuição nos teores desses nutrientes na dieta para os níveis mais altos de CAI (Tabela 2).

Os coeficientes de digestibilidade de matéria seca (CDMS), matéria orgânica (CDMO) e carboidratos totais (CDCHT) não sofreram influência $(\mathrm{P}>0,05)$ da oleaginosa na dieta, com valores médios de 64,48; 69,87 e 67,05\%, respectivamente (Tabela 5). Estes resultados são contrários aos relatados por Warren et al. (1988), que forneceram 0; 25 e $50 \%$ de CAI, respectivamente, com 8, 1, e 12,6\% de EE, e Karalazos et al. (1992), que notaram depressão linear significativa no coeficiente de digestibilidade da MS e MO com o aumento do caroço de algodão de 0 a 53\% na dieta. Também Zinn (1989) verificou diminuição linear da digestão ruminal da MO com aumento do nível de óleo como suplemento de 0 a $8 \%$, o que pode ser creditado ao 
Tabela 5 - Coeficiente de digestibilidade (CD) dos nutrientes das dietas em ovinos Santa Inês alimentados com diferentes níveis de caroço de algodão integral na dieta

\begin{tabular}{|c|c|c|c|c|c|c|c|}
\hline \multirow[t]{2}{*}{ CD } & \multicolumn{4}{|c|}{ Nível de caroço de algodão integral (\%) } & \multirow[b]{2}{*}{ Regressão } & \multirow[b]{2}{*}{$\mathrm{R}^{2}$} & \multirow[b]{2}{*}{ CV (\%) } \\
\hline & 0 & 20 & 30 & 40 & & & \\
\hline MS & 69,43 & 67,57 & 66,62 & 70,32 & $\hat{\mathrm{Y}}=64,48$ & - & 5,07 \\
\hline MO & 69,77 & 69,27 & 68,70 & 71,77 & $\hat{\mathrm{Y}}=69,87$ & - & 4,90 \\
\hline FDN & 54,70 & 54,95 & 61,60 & 63,11 & $\hat{\mathrm{Y}}=53,489+0,227 * \mathrm{X}$ & 0,79 & 9,82 \\
\hline CNF & 84,70 & 84,70 & 76,50 & 79,87 & $\hat{\mathrm{Y}}=85,2133-0,16466 * \mathrm{X}$ & 0,99 & 6,40 \\
\hline СHT & 69,60 & 66,98 & 65,13 & 66,50 & $\hat{\mathrm{Y}}=67,05$ & - & 5,44 \\
\hline
\end{tabular}

** Significativo a $1 \%$ de probabilidade pelo teste $\mathrm{F}$.

impacto da gordura na dieta, que pode deprimir a digestibilidade da fibra. No entanto, essa influência depende da fonte, do processamento e nível de inclusão do suplemento.

O coeficiente de digestibilidade de PB apresentou efeito quadrático $(\mathrm{P}>0,01)$ e o de $\mathrm{EE}$, efeito linear crescente $(\mathrm{P}<0,01)$ em relação ao aumento dos níveis de CAI. Os valores médios de digestibilidade de PB e EE foram semelhantes aos citados pela FAO (1992) para a digestibilidade destes nutrientes (68,4 e 86,6\%, respectivamente).

A análise de regressão do CDPB mostrou que o menor valor ocorreu na dieta com $20 \%$ de CAI, com ponto de mínimo de 72,08\%, enquanto para o CDEE mostrou efeito linear crescente com a inclusão do CAI na dieta, ou seja, não houve redução da digestibilidade quando o teor de óleo na dieta foi de 9\%. Borges et al. (2002), trabalhando com níveis de caroço de algodão semelhantes aos deste trabalho, verificaram que a inclusão de CAI às dietas melhorou a digestão da PB e do EE, sem afetar o consumo de MS. Também Coppock et al. (1987) e Brosh et al. (1989) relataram que, à medida que se incorporou CAI na dieta, elevaram-se o consumo e a digestibilidade do EE de forma linear.

Os valores para os coeficientes de digestibilidade de PB e EE apresentaram alta correlação $\left(R^{2}=0,99, P<0,01\right)$, em decorrência do elevado consumo desses nutrientes, que é atribuído à presença de CAI, que proporcionou ambiente ruminal favorável aos microorganismos. Smith \& Vosloo (1990) também constataram aumentos na digestibilidade de EE nas dietas mais concentradas em caroço de algodão, fato também confirmado por Karalazos et al. (1992), que observaram aumento linear da digestibilidade de EE com o aumento dos teores de CAI de 0,0 para $35,5 \%$ da dieta.

Observa-se que, entre os níveis de inclusão, o maior CDPB das dietas foi para o nível de $40 \%$ de CAI, demonstrando que esse ingrediente em maior quantidade na dieta refletiu em aumento da digestibilidade protéica. Da mesma forma, Brosh et al. (1989) verificaram que incremento no conteúdo de PB, devido à elevação do CAI na dieta, melhorou o desenvolvimento da flora ruminal e o processo de fermentação, o que pode ser atribuído ao aumento na taxa de passagem de material nitrogenado para o intestino delgado conforme comentários de Zinn \& Plascencia (1993). Segundo Palmquist (1989), a vantagem da utilização de lipídios em dietas deve-se ao incremento da densidade calórica da dieta, em razão de seu elevado valor energético (aproximadamente $6 \mathrm{Mcal}$ El/kg MS), e pode ser explorada de várias maneiras, além de permitir aumento no consumo de energia e balanço mais adequado entre carboidratos estruturais e não-estruturais para a otimização do consumo de fibra e energia digestível.

Em relação às frações fibrosas, os coeficientes de digestibilidade apresentaram comportamento linear ascendente $(\mathrm{P}<0,01)$ para o CDFDN, conforme os crescentes níveis de CAI (54,70; 54,95; 61,60 e 63,11\%), provavelmente em razão da maior concentração desse nutriente no feno de Tifton e CAI, e resposta quadrática $(\mathrm{P}<0,01)$ para CDFDA, demonstrando alta correlação entre consumo e digestibilidade $\left(\mathrm{R}^{2}=0,99 ; \mathrm{P}<0,01\right)$. Estes resultados divergem daqueles obtidos por Borges et al. (2002), Rogério et al. (2004) e Teixeira et al. (2005), que relataram decréscimo no consumo e na digestibilidade da FDN e FDA com o aumento do CAI em rações de ovinos.

A composição da ração e o preparo e efeito associativo dos alimentos podem afetar sua digestibilidade. A não influência da gordura oriunda do CAI na digestibilidade dos nutrientes pode ter ocorrido pelo fato de o caroço de algodão ter um revestimento composto na maior porcentagem por fibra e por possuir línter. Estas características proporcionam lenta liberação da gordura no ambiente ruminal no decorrer do dia, devido à regurgitação e 
remastigação das sementes. Isto permite a ação dos microrganismos ruminas em hidrogenar as ligações duplas dos ácidos graxos insaturados, impedindo o efeito inibidor da gordura sobre a digestibilidade da fibra (Coppock \& Wilks, 1991).

Sabe-se que ruminantes não toleram altos níveis de óleo na dieta; entretanto, Smith et al. (1981) sugeriram que a inclusão de sementes integrais de oleaginosas não tem influência negativa sobre a degradação da fibra total no intestino, o que corrobora os resultados obtidos neste estudo. Também Palmiquist \& Mattos (2006) verificaram que a suplementação lipídica, superior a 5\%, comprometeu o consumo de MS, porém, em animais de confinamento em regiões de altas temperaturas, em que o consumo geralmente é comprometido, a suplementação lipídica pode chegar a $10 \%$ e, neste caso, aumenta a ingestão de energia.

O CDCHT não foi influenciado pelas dietas (69,60; 66,98; 65,13 e 66,50\%), enquanto o CDCNF mostrou efeito linear decrescente $(\mathrm{P}<0,01)$, que pode ser devido ao nível de CNF da dieta (Tabela 2), semelhante ao consumo, que também foi decrescente. Provavelmente, o efeito associativo dos alimentos na ração pode ter restringido essa fração de carboidratos, os quais são rapidamente degradados no rúmen.

\section{Conclusões}

A inclusão do caroço de algodão nos níveis estudados em dietas para ovinos não alterou o consumo de MS, mas deprimiu o ganho de peso e diminuiu a conversão alimentar.

A inclusão do caroço de algodão melhorou a digestibilidade da FDN, sem alterar as digestibilidades de MS e MO e o consumo de nutrientes digestíveis.

\section{Literatura Citada}

ARIELI, A. Effect of whole cottonseed on partitioning of energy and nitrogen balance in sheep. Animal Production, v.58, n.1, p.103-108, 1994.

ARIELI, A. Whole cottonseed in dairy cattle feeding: a review. Animal Feed Science and Technology, v.72, p.97-110, 1998.

ALVES, K.S.; CARVALHO, F.F.R.; VERAS, A.S.C. et al. Níveis de energia em dietas para ovinos Santa Inês: desempenho. Revista Brasileira de Zootecnia, v.32, n.6, p.1937-1944, 2003 (supl. 2).

AFERRI, G.; LEME, P.R.; SILVA, S.L. et al. Desempenho e características de carcaça de novilhos alimentados com dietas contendo diferentes fontes de lipídios. Revista Brasileira de Zootecnia, v.34, p.1651-1658, 2005.

BROSH, A.; HOLTZER, Z.; LEVY, D. Cottonseed for protein and energy supplementary of high-roughage diets for beef cattle. Animal Production, v.48, n.3, p.513-518, 1989.

BORGES, I.; SILVA, A.G.M.; RODRIGUEZ, M.N. et al. Efeito da adição do caroço de algodão integral sobre parâmetros nutricionais de dietas para ovinos contendo feno de braquiária
(Brachiaria decumbens) ou Tifton 85 (Cynodon spp). In: REUNIÃO ANUAL DA SOCIEDADE BRASILEIRA DE ZOOTECNIA, 39., 2002, Recife. Anais... Recife: Sociedade Brasileira de Zootecnia, 2002. (CD-ROM).

COPPOCK, C.E.; LANHAM, J.K.; HORNER, J.L. A review of the nutritive value and utilization of whole cottonseed, cottonseed meal and associated by-products by dairy cattle. Animal Feed Science and Technology, v.18, n.1, p.89-129, 1987.

COPPOCK, C.E.; WILKS, D.L. Supplemental fat in high energy ration for lactating cows: effects on intake, digestion, milk yield and composition. Journal of Animal Science, v.69, n.9, p.3826-3837, 1991.

CARDOSO, A.R.; PIRES, C.C.; CARVALHO, D. et al. Consumo de nutrientes e desempenho de cordeiros alimentados com dietas que contem diferentes níveis de fibra em detergente neutro. Ciência Rural, v.36, n.1, p.215-221, 2006.

FOOD AGRICULTURE ORGANIZATION UNITED NATIONS FAO. [1992]. Tropical feeds. 3.0. OxfordOxfordComputer Journals. Disponível em: < http://www.fao.org/waicent/faoinfo/ agricult/aga/agap/frg/tfeed8/index.htm.> Acesso em: 15/9/2004

HALL, M.B.; HOOVER, W.H.; JENNINGS, J.P. et al. A method for partitioning neutral detergent soluble carbohydrates. Journal Science Food Agriculture, v.79, p.2079-2086, 1999.

HADDAD, S.G.; YOUNIS, H.M. The effect of adding ruminally protected fat in fatting diets of nutrient intake, digestibility and growth performance of Awassi lambs. Animal Feed Science and Technology, v.113, p.61-69, 2004

KARALAZOS, A.; DOTAS, D.; BIKOS, J. A note on the apparent digestibility and nutritive value of whole cottonseed given to sheep. Animal Production, v.55, p.285-287. 1992.

LUDOVICO, A.; MATTOS, W.R.S. Avaliação de dietas à base de cana-de-açúcar (Saccharum officinarum L) e diferentes níveis de sementes de algodão (Gossypium hirsutum L.). Revista Brasileira de Zootecnia, v.26, n.2, p.403-410, 1997.

LUNGINBUHL, J.M.; POORE, M.H.; CONRAD, A.P. Effect of level of whole cottonseed on intake, digestibility, and performance of growing male goats fed hay-based diets. Journal of Animal Science, v.78, n.6, p.1677-1683. 2000.

MOORE, J.A.; SWINGLE, R.S.; HALE, W.H. Effects of whole cottonseed oil or animal fat on digestibility of wheat straw diets by steers. Journal of Dairy Science, v.63, p.1267-1273, 1986.

MOORE, J.A.; POORE, M.H.; POND, K.R. Performance of lambs fed varying levels of whole cottonseed. Journal of Animal Science, v.72, p.382, 1994 (suppl. 1).

MERTENS, D.R. Regulation of forage intake. In: FAHEY JR., G.C. (Ed.) Forage quality, evaluation and utilization. Madison: American Society of Agronomy, 1994. p.450-493.

MEDEIROS, A.N.; HONORIO, F.O.; LISBOA, O.V. et al. Desempenho de cordeiros Santa Inês alimentados com farelo de girassol. In: REUNIÃO ANUAL DA SOCIEDADE BRASILEIRA DE ZOOTECNIA, 40., 2003, Santa Maria. Anais... Santa Maria: Sociedade Brasileira de Zootecnia, 2003. (CD-ROM).

MEDEIROS, G.R. Efeito de níveis de concentrado sobre o desempenho, característica de carcaça e componentes não carcaça de ovinos Morada Nova em confinamento. Recife: Universidade Federal Rural de Pernambuco, 2006. 108p. Tese (Doutorado em Zootecnia) - Universidade Federal Rural de Pernambuco, 2006.

NATIONAL RESEARCH COUNCIL - NRC. Nutrient requirements of sheep. 6.ed. Washington, D.C.: National Academy Press, 1985. 99p.

PALMQUIST, D.L.; JENKINS, T. Fat in lactation ration: a review. Journal of Dairy Science, v.63, n.1, p.1-14, 1980.

PALMQUIST, D.L. The feeding values of fat. In: TRIBE, E.; ORSKOV, R. (Eds.) World animal science (Feedstuffs). The Netherlands: Elsevier Science Publishers, 1988. p.239-311.

PALMQUIST, D.L. Suplementação de lipídeos para vacas em lactação. In: SIMPÓSIO SOBRE PRODUÇÃO ANIMAL, 1989, 
Piracicaba. Anais... Piracicaba: Fundação de Estudos Agrários Luiz de Queiroz, 1989. p.11-26.

PALMQUIST, D.L.; MATTOS, W.R S. Metabolismo de lipídeos. In: BERCHIELI, T.T.; PIRES, A.V.; OLIVEIRA, S.G. et al. (Eds.) Nutrição de ruminantes. Jaboticabal: Funep, 2006. p.287-310.

PETIT, H.V.; RIOUX, R.; D'OLIVEIRA, P.S. et al. Performance of growing lambs ed silage with raw or extrused soybean or canola seeds. Canadian of Journal Animal Science, v.77, p.445-463, 1997.

ROGERIO, M.C.P.; BORGES, I.; RODRIGUEZ, N.M. et al. Efeito da inclusão do caroço de algodão sobre o consumo, digestibilidade e balanço da energia em dietas para ovinos. Arquivo Brasileiro de Medicina Veterinária e Zootecnia, v.54, n.5, p.478-484, 2002. RODRIGUES, M.M.; NEIVA, J.N.M.; VASCONCELOS, V.R. et al. Utilização do farelo de castanha de caju na terminação de ovinos em confinamento. Revista Brasileira de Zootecnia, v.32, n.1, p.240-248, 2003.

ROGERIO, M.C.P.; TEIXEIRA, D.A.B.; RODRIGUEZ, N.M. et al. Efeito do nível de caroço de algodão sobre a digestibilidade da fibra dietética do feno de Tifton 85 (Cynodon spp.) em ovinos. Arquivo Brasileiro de Medicina Veterinária e Zootecnia, v.55, n.5, p.665-670, 2004.

SMITH, N.E.; COLLAR, L.S.; BATH, D.L. et al. Digestibility and effects of whole cottonseed fed to lactating cows. Journal of Dairy Science, v.64, n.11, p.2209-2215, 1981.

SMITH, W.A.; VOSLOO, L.P. Digestibility of diets containing cottonseed and the effect of supplementary lanolin thereon in sheep. South African Journal of Animal Science, v.20, n.4, p.216-222, 1990.

SNIFFEN, C.J.; O’ CONNOR, J.D.; Van SOEST, P.J. et al. A net carbohydrate and protein system for evaluating cattle diets: II. Carbohydrate and protein availability. Journal of Animal Science, v.70, p.3562-3577, 1992.

SOUTO, P.R.L.; MILAGRES, J.C.; SILVA, M.A. et al. Consumo, digestibilidade, reações fisiológicas e componentes sangüíneos de ovinos submetidos a diferentes temperaturas e a dietas com diferentes níveis de energia. I. Consumo de alimento e ingestão de água. Pesquisa Agropecuária Brasileira, v.25, n.9, p.1247-1251, 1990.

SRIDHAR, V.; JANARDHANA REDDY, T.; RAGHAVA RAO, E. et al. Nutrient digestibilities as influenced by dietary energy levels in Deccani lambs. Indian Journal of Animal Nutrition, v.13, n.1, p.53-55, 1996.

STATISTICAL ANALYSIS SYSTEM - SAS. User's guide to statistics. Versão 8. Cary: SAS Institute, 1999. 956p.
SILVA, D.J.; QUEIROZ, A.C. Análises de alimentos: métodos químicos e biológicos. 3.ed. Viçosa, MG: Editora UFV, 2002. $166 \mathrm{p}$.

TEIXEIRA, D.B.; BORGES, I. Efeito do nível de caroço de algodão sobre o consumo e digestibilidade da fração fibrosa do feno de braquiária em ovinos (Brachiaria decumbes) em ovinos. Arquivo Brasileiro de Medicina Veterinária e Zootecnia, v.57, n.2, p.229-233, 2005.

URANO, F.S.; PIRES, A.V.; SUSIN, I. et. al. Desempenho e características da carcaça de cordeiros confinados alimentados com grão de soja. Pesquisa Agropecuária Brasileira, v.41, n.1, p.1525-1530, 2006.

Van SOEST, P.I.; ROBERTSON, J.D.; LEWIS, B.A. Methods for dietary fiber, neutral detergent fiber, nonstarch polysaccharides in relation to animal nutrition. Journal of Dairy Science, v.74, n.11-12, p.3583-3597, 1991.

Van SOEST, P.J. Nutritional ecology of the ruminant. 2.ed Ithaca: Cornell University Press, 1994. 476p.

VERAS, R.M.L.; FERREIRA, M.A.; ARAUJO, C.V. et al. Farelo de palma forrageira (Opuntia fícus indica Mill) em substituição ao milho. Digestibilidade dos nutrientes. Revista Brasileira de Zootecnia, v.31, n.3, p.1302-1306, 2002.

VERAS, R.M.L.; FERREIRA, M.A.; ARAUJO, C.V. et al. Substituição do farelo de palma forrageira (Opuntia fícus indica Mill) em dietas de ovinos em crescimento. I. Desempenho. Revista Brasileira de Zootecnia, v.34, n.1, p.249-256, 2005.

ZINN, R. Influence of level and source of dietary fat on its comparative feeding value in finishing diets for feedlot steers: metabolism. Journal of Animal Science, v.67, n.3-4, p.10381049, 1989.

ZINN, R.A.; PLASCENCIA, A. Interaction of whole cottonseed and supplemental fat on digestive function in cattle. Journal of Animal Science, v.71, n.1, p.11-17, 1993.

WARREN, H.; NEUTZE, S.A.; MORRISON, J. M. et al. The value of whole cottonseed in a wheat-based maintenance ration for sheep. Australian Journal Experimental Agriculture, v.28, n.1-2, p.453-458, 1988.

WILKS, D.L.; COPPOCK, C.E.; BROOKS, K.N. Effects of differences in starch content of diets with whole cottonseed or rice bran on milk casein. Journal of Dairy Science, v.74, n.4, p.1314-1320, 1991.

WEISS, W.P. Energy predicton equations for ruminant feeds. In: CORNEL NUTRITION CONFERENCE FEED MANUFACTURES, 61., 1999, Ithaca. Proceedings... Ithaca: Cornell University, 1999. p.176-185. 